\title{
Practicing Green Residence Business Model Based on TPB Perspective
}

\author{
Chao $\mathrm{Wu}^{1}$, Shuling Liang ${ }^{2}$, Weijiong $\mathrm{Wu}^{3, *}$ and Yuxiang Hong ${ }^{4, *}$ \\ 1 Propaganda Department, Hangzhou Dianzi University, Hangzhou 310018, China; we926@hdu.edu.cn \\ 2 Hangxiao Steel Structure Co., LTD., Hangzhou 310018, China; liang.shuling@hxss.com.cn \\ 3 School of Management, Guangdong University of Technology, Guangzhou 510006, China \\ 4 School of Management, Hangzhou Dianzi University, Hangzhou 310018, China \\ * Correspondence: psyjohn@foxmail.com (W.W.); hongyx@hdu.edu.cn (Y.H.)
}

check for

updates

Citation: Wu, C.; Liang, S.; Wu, W.; Hong, Y. Practicing Green Residence Business Model Based on TPB

Perspective. Sustainability 2021, 13, 7379. https://doi.org/10.3390/ su13137379

Received: 25 April 2021

Accepted: 24 June 2021

Published: 1 July 2021

Publisher's Note: MDPI stays neutral with regard to jurisdictional claims in published maps and institutional affiliations.

Copyright: (c) 2021 by the authors. Licensee MDPI, Basel, Switzerland. This article is an open access article distributed under the terms and conditions of the Creative Commons Attribution (CC BY) license (https:/ / creativecommons.org/licenses/by/ $4.0 /)$.

\begin{abstract}
Green residence is the future of urban development, it is also an attempt to implement the green business model in the residential business field. The key to the success of a green business model is that a wide range of customers can accept its green value proposition and react to it through their purchase decisions. This study aims to develop a theory of a planned behavior (TPB) research model to predict individuals' intention to purchase green residence. This study took steel structure residence as an example, which was widely recognized as one emerging type of green residence. The samples were selected in Baotou city of Inner Mongolia, P.R. China. Data analysis was performed using the structural equation modeling (SEM) with data obtained from a survey of 208 respondents using SPSS19.0 and AMOS17.0. The results found that the individuals' intention to purchase green residence was significantly affected by attitude, subjective norm, and perceived behavioral control. Moreover, the empirical evidence showed that these influences differed between different gender groups. Specifically, women responders had a stronger effect on the path attitude impact on purchase intention than men. These findings can provide implications for practicing the green business model of real estate enterprise.
\end{abstract}

Keywords: the theory of planned behavior (TPB); green residence; green business model; purchase intention

\section{Introduction}

As more and more attention is paid to the environmental problem, the need for a green business model for enterprises has grown in importance [1]. A green business model refers to business plans that support the promotion of products and services that can balance the relationship between economical and environmental benefits [2]. The key to the success of a green business model is that a wide range of customers can accept its green value proposition and react to it through their purchase decisions. Green building is the practice of creating and using healthier and more resource-efficient models of construction, renovation, operation, maintenance, and demolition, and a green residence is an important part of a green building, which is an attempt to implement a green business model in the residential business field. More people are accepting the advantages of green residence today with the development of the concept of sustainable consumption. However, as a high-value consumer product, the green residence purchase decision-making process is overly complicated, while usually affected by the guidance of policy, the influence of family and friends, the restriction of purchasing knowledge and information, as well as the attitude toward the green residence purchase behavior. In this study, we empirically test the influence mechanism of green residence purchase intention based on the theory of planned behavior (TPB). We found that TPB theory has a good explanatory power on consumers' green residence purchase decision-making. Moreover, we also expanded the boundary of the TPB model by exploring the moderating effect of genders and purchasing experiences on the process of purchase decision-making. These findings can provide a 
more targeted and operational reference for the value proposition of green residences. The remainder of the paper is organized as follows. Section 2 presents the theoretical analysis and research hypotheses. Section 3 presents the methodology in detail, including participants, measurement, and data analysis. Section 4 outlines the results of the analysis. Sections 5 and 6, respectively, shows the discussion and conclusion.

\section{Theoretical Analysis and Research Hypotheses}

TPB is an important theory for explaining the personal behavioral decision-making process, which is developed on the theory of reasoned action by Ajzen (1991) [3]. TPB considers all the possible factors affecting behavior that can indirectly affect behavior by behavioral intention. In turn, behavioral intention is impacted by attitude toward the behavior, subjective norm, and perceived behavioral control. Attitude toward the behavior refers to the degree of an individual's positive or negative personal evaluation of a specific behavior. Subjective norm refers to the social pressure exerted to engage in a specific behavior, including the expectation from family, friends, or other important referents. Perceived behavioral control is the degree of difficulty that an individual perceived for carrying out a specific behavior. TPB has been wildly applied in the areas of green consuming, such as green food [4], green personal care products [5], and green hotels [6]. Green residence purchasing is a typical personal behavioral decision-making process and can be explained by the TPB model.

First, with the popularity of the green consumption concept, the purchasing experience of a green residence can be connected with "fashion", as compared to traditional housing. Particularly, green residence purchasing is unique in terms of value creation for customers. The more consumers perceive this unique value experience, the more likely they are to "pay" for it. According to TPB, firstly, attitude is an important predictor of behavioral intention. Many existing literatures had verified the significant positive effect of attitude impacting on intention [7-10], as well as verifying it in the situation of residence purchasing [11,12]. Second, although green buildings have gradually become popular, most of them are public buildings (i.e., stadiums, airports), and the proportion of green residence is still small. The development of the green residence market still needs the guidance of policy and the establishment of public reputation. If there are more peripheral people and with the guidance of public opinion, individuals will be more willing to buy public reputation. The positive effect that subjective norms impacted on behavioral intention had been verified in many existing literature [13-15]. It was also verified in the situation of residence purchasing that social pressure from family, friends, and social culture can positively influence the purchasing intention [11,16-19]. Third, as a high-value product, the purchase of green buildings requires a certain economic strength. Further, the purchase of housing also needs to consider the location, the surrounding environment, the future value added and other complex elements that require the corresponding knowledge and skills. Therefore, when individuals believe they have these strengths, their purchase intention will be strong. The positive roles of perceived behavioral control on the improvement of purchase intention had also been verified in previous studies $[11,13,20]$. Fourth, behavioral attitudes, subjective norms, and perceived behavioral control can be completely differentiated conceptually, but they are correlated in pairs. The more positive individuals' attitude toward specific behavior is, the more likely they are to accept suggestions from people around them, and the more they are willing to prepare to practice this behavior. The stronger the consumers' perceived behavior control is, the greater the pressure they feel from the people around them, and the more they expect a unique purchasing experience. The stronger the subjective norms of individuals are, the more likely they are to prepare for consumption and the more positive their attitude toward purchase behavior is. Therefore, hypotheses $1-4$ were proposed:

Hypothesis 1 (H1). Attitude has a positive influence on green residence purchase intention.

Hypothesis 2 (H2). Subjective norms have a positive influence on green residence purchase intention. 
Hypothesis 3 (H3). Perceived behavioral control has a positive influence on green residence purchase intention.

Hypothesis 4 (H4). Attitude, subjective norms, perceived behavioral control have significant reciprocal effects.

Many studies had found significant differences in consumer behaviors of different genders [21-25]. For example, Darley et al. (1995) [21] and Laroche et al. (2000) [22] believed that different genders had different decision-making processes. Women tend to pay more attention to details and take a comprehensive approach to information processing, while men tend to take a heuristic approach and do not pay attention to details when making decisions. Melnyk and van Osselaer (2012) considered that men are more positive to loyalty items that emphasize status and have a higher degree of collective dependence, while women are more positive to items that emphasize individuation and have a higher degree of dependence on inter-individual relations [26]. In the field of green consumption, Laroched et al. (2001) [22] empirically verified that women care more about the environment than men and are more willing to buy green products. Moreover, existing literature in different fields had verified that past experience is an important influencing variable of behavioral intention [27-30]. In the field of green consumption, Kim et al. (2011) added consumers' past purchase experience as a predictor in parallel with behavioral attitude, subjective norms, and perceived behavioral control into the TPB model, and the empirical results found that consumers' past experience had a positive impact on consumption intention [5]. Han et al. (2010) added the frequency of past experience to the TPB model as a predictive variable of consumption intention, and the empirical results indicated that the frequency of past experience had a positive impact on consumption intention [6]. However, they took experience as a predictive variable and did not consider its interaction with attitudes, subjective norms, and perceived behavioral control. As a high-value fixed asset, it is difficult for the past purchase experience to directly affect the purchase intention. Therefore, this study believes that the experience may impact on the purchase intention through the interaction effects with attitude, subjective norms, and perceived behavioral control. Therefore, the following hypotheses were proposed:

Hypothesis 5 (H5). In the decision-making process of green residence purchase, a significant difference exists among consumers of different genders.

Hypothesis 6 (H6). In the decision-making process of green residence purchase, a significant difference exists among consumers with and without purchase experience.

\section{Method}

\subsection{Study Participants}

The sample in this study are the consumers of a steel structure residence project located in Baotou city of China. Steel structure residence is one the most typical green residences in China; however, it is still relatively rare compared with rigid concrete residences. The project we chose in Baotou is a national steel structure residences industrialization demonstration community, approved by the Ministry of Construction as "energy-saving and environmentally friendly residence". To be able to obtain data from both consumers with and without purchase experience, the survey was divided into two sub-groups. According to the sample sizes of previous studies [31-33], in one sub-group, 120 respondents were randomly selected from a list of current owners of the residence project using a doorto-door survey, and 114 respondents finished the questionnaires; in the other sub-group, 120 respondents were randomly selected from the house viewers in the sales office using an on-site visit, and 94 respondents finished the questionnaires. A total of 208 valid questionnaires were obtained with a response rate of $86.7 \%$. Of these, $48.56 \%$ were from men and 
$51.44 \%$ were from women. Table 1 shows the crosstab of the demographic characteristics and purchase experience of the responders.

Table 1. Crosstab of the demographic characteristics and purchase experience.

\begin{tabular}{ccccc}
\hline Demographic Factors & Groups & With PE & Without PE & Total \\
\hline \multirow{2}{*}{ Gender } & Men & $46.49 \%$ & $51.06 \%$ & $48.56 \%$ \\
& Women & $53.51 \%$ & $48.94 \%$ & $51.44 \%$ \\
\hline \multirow{2}{*}{ Age } & $18-20$ & $2.63 \%$ & $6.38 \%$ & $4.33 \%$ \\
& $21-30$ & $22.81 \%$ & $30.85 \%$ & $26.44 \%$ \\
& $31-40$ & $41.23 \%$ & $37.23 \%$ & $39.42 \%$ \\
& $41-50$ & $24.56 \%$ & $14.89 \%$ & $20.19 \%$ \\
& $51-60$ & $5.26 \%$ & $8.51 \%$ & $6.73 \%$ \\
& $>60$ & $3.51 \%$ & $2.13 \%$ & $2.88 \%$ \\
\hline \multirow{5}{*}{ Education } & Junior high & $11.40 \%$ & $9.57 \%$ & $10.58 \%$ \\
& school & $44.74 \%$ & $21.28 \%$ & $34.13 \%$ \\
& High school & $24.56 \%$ & $43.62 \%$ & $33.17 \%$ \\
& College & $15.79 \%$ & $19.15 \%$ & $17.31 \%$ \\
& Bachelor & $3.51 \%$ & $6.38 \%$ & $4.81 \%$ \\
\hline \multirow{2}{*}{ Family income/year } & Master/Phd & $25.44 \%$ & $8.51 \%$ & $17.79 \%$ \\
(thousand RMB) & $<30$ & $49.12 \%$ & $19.15 \%$ & $35.58 \%$ \\
& $31-80$ & $10.53 \%$ & $36.17 \%$ & $22.12 \%$ \\
& $80-120$ & $7.89 \%$ & $23.40 \%$ & $14.90 \%$ \\
& $120-200$ & $4.39 \%$ & $9.57 \%$ & $6.73 \%$ \\
& $200-300$ & $2.63 \%$ & $3.19 \%$ & $2.88 \%$ \\
\hline
\end{tabular}

\subsection{Measures}

The measurements of attitude, subjective norms, perceived behavioral control, and purchase intention were adapted from the existing literature [34-37], all the items were recorded on a five-point Likert scale that ranged from one (do not agree at all) to five (strongly agree). Specifically, attitude was measured using three items: (i) "Buying a steel structure residence can be an interesting experience", (ii) "Buying a steel structure residence can reflect my taste", and (iii) "Buying a steel structure residence is of value". Subjective norms were measured using three items: (i) "My friend thinks I should buy a steel structure residence", (ii) "My family thinks I should buy a steel structure residence", and (iii) "The policy supports me to buy a steel structure residence". Perceived behavioral control was measured using three items: (i) "I know a lot about the functions of steel structure residence", (ii) "I have a lot of information about steel structure residence", and (iii) "I am well aware of the advantages and disadvantages of a steel structure residence". Purchase intention was measured using three items for the respondents without purchase experiences: (i) "I intend to buy a steel structure residence", (ii) "I would like to buy a steel structure residence", (iii) "I may buy a steel structure residence". For the respondents with purchase experiences, it was measured by (i) "next time when buying a house, I intend to buy a steel structure residence", (ii) "next time when buying a house, I would like to buy a steel structure residence," and (iii) "next time when buying a house, I may buy a steel structure residence". Gender and purchase experience were used as moderating variables. For the gender measure, the man was set to "1" and the woman was set to " 2 ". For the measurement of purchasing experience, with experience was set to " 1 " and without experience were set to " 0 ". Additionally, family income, education, and age were also included as control variables, which were verified to significantly affect purchase intention $[23,38]$. 


\subsection{Data Analysis}

This study tested the adequacy of measurements using a confirmatory factor analysis (CFA). The hypotheses were tested by structural equation modeling (SEM). SPSS19.0 and AMOS17.0 were used to analyze the data.

\section{Results}

\subsection{Preliminary Analysis}

The Cronbach's $\alpha$ coefficient of attitude, subjective norms, perceived behavioral control, and purchase intention were $0.838,0.811,0.896$, and 0.902 , respectively. It confirmed that the questionnaire had good internal consistency. The result showed that the KaiserMeyer-Olkin value was $0.939>0.80$, and the Bartlett's Test of Sphericity was significant. This result indicated that the data had good structure validity and was suitable for factor analysis.

Before structural equation analysis, the maximum likelihood estimation method was used to evaluate the fitness of the measurement model. The goodness-of-fit was measured by a combination approach: relative chi-square $\left(x^{2} / \mathrm{df}\right.$, less than 3 in a wellfitting model), the root-mean-square error of approximation (RMSEA, less than 0.08 in a well-fitting model), goodness-of-fit index(GFI, higher than 0.9 in a well-fitting model), adjusted goodness-of-fit index(AGFI, higher than 0.9 in a well-fitting model), Normed fit index (NFI, higher than 0.9 in a well-fitting model), and comparative fit index (CFI, higher than 0.9 in a well-fitting model).The results indicated that the measurement model exhibited a good fit with the data $\left(\chi^{2} / \mathrm{df}=1.084, \mathrm{RMSEA}=0.020, \mathrm{GFI}=0.960, \mathrm{AGFI}=0.933\right.$, $\mathrm{NFI}=0.973, \mathrm{CFI}=0.998$, all of which were in the ideal range). Meanwhile, the convergence validity of the measurement model requires that the standardized factor load should be above 0.5 , the combined reliability (C.R.) should be greater than 0.7 , and the mean extraction variance (AVE) should be greater than 0.5 . The CFA result was shown in Table 2, which indicated that the convergent validity was acceptable.

Table 2. Factor loading of items.

\begin{tabular}{ccccc}
\hline Constructs & Items & Loading & C.R. & AVE \\
\hline \multirow{2}{*}{ AT } & AT1 & 0.720 & & \\
& AT2 & 0.774 & 0.780 & 0.542 \\
& AT3 & 0.712 & & \\
SN & SN1 & 0.753 & 0.804 & 0.579 \\
& SN2 & 0.821 & & \\
& SN3 & 0.704 & 0.615 \\
PBC & PBC1 & 0.807 & & \\
& PBC2 & 0.787 & 0.718 \\
& PBC3 & 0.757 & 0.884 & \\
\hline PI & PI1 & 0.831 & & \\
& PI2 & 0.854 & & \\
\hline
\end{tabular}

\subsection{Hypotheses Testing of Overall Sample}

The structural equation model is used to verify the research hypothesis. First, the maximum likelihood estimation method was used to test the fitness of the structural model. The results indicated that the structural model exhibited a good fit with the data (shown in Table $3, \chi^{2} / \mathrm{df}=1.258, \mathrm{RMSEA}=0.035, \mathrm{GFI}=0.939, \mathrm{AGFI}=0.910, \mathrm{NFI}=0.948, \mathrm{CFI}=0.989$ ). The path coefficients in the model are all significant $(p<0.05)$. Specifically, individuals attitudes toward green residence purchase (H1: $\beta=0.257, p<0.01)$, subjective norms (H2: $\beta=0.575, p<0.001)$, and perceived behavioral control (H3: $\beta=0.173, p<0.05)$ have significant positive impacts on their purchase intention. Moreover, the results also supported the hypothesis that significant pair interactions among attitude, subjective norms, and perceived behavioral control exist. Specifically, the interaction between attitude and 
subjective norms was significant $(\beta=0.779, p<0.001)$, the interaction between subjective norms and perceived behavioral control was significant $(\beta=0.765, p<0.001)$, and the interaction between perceived behavioral control and attitude was significant $(\beta=0.726$, $p<0.001)$. H4 was thus supported.

Table 3. Results of SEM.

\begin{tabular}{cccc}
\hline Hypotheses & Paths & Coefficients & Results \\
\hline $\mathrm{PI}<-\mathrm{AT}$ & $0.257^{* *}$ & Sig. & H1 was supported \\
$\mathrm{PI}<-\mathrm{SN}$ & $0.575^{* * *}$ & Sig. & H2 was supported \\
$\mathrm{PI}<-\mathrm{PBC}$ & $0.173^{*}$ & Sig. & H3 was supported \\
$\mathrm{SN}<->\mathrm{AT}$ & $0.779^{* * *}$ & Sig. & \\
$\mathrm{PBC}<->\mathrm{SN}$ & $0.765^{* * *}$ & Sig. & H4 was supported \\
$\mathrm{AT}<->\mathrm{PBC}$ & $0.726^{* * *}$ & Sig. & \\
Note. $^{*} p<0.05 ;{ }^{* *} p<0.01^{* * *} p<0.001$. & &
\end{tabular}

\subsection{Tests for Group Differences}

\subsubsection{Invariance Test of Measurement Model}

Before we conducted the test, the sample was divided into male and female groups and into "with" and "without" experiences groups. Then measurement invariance was tested, where the CFA results were compared between the non-restricted model (without constraining any factor loading across groups) and full-metric invariance (all factor loadings were constrained to be equal between groups). The results (shown in Table 4) indicated that the chi-square difference between the non-restricted model and full-metric invariance model was not significant for both gender $\left(\Delta \chi^{2}=21.809, \Delta \mathrm{df}=18, p>0.01\right)$ and experiences $\left(\Delta \chi^{2}=29.059, \Delta \mathrm{df}=18, p>0.01\right)$ groups. Therefore, the invariance of the measurement models was supported.

Table 4. Measurement invariance test.

\begin{tabular}{clccccccccc}
\hline Groups & Model & $\chi^{2}$ & df & $\chi^{2} / \mathbf{d f}$ & RMSEA & GFI & AGFI & NFI & CFI & $\Delta \chi^{2}$ \\
\hline \multirow{2}{*}{ Gender } & Non-restricted model & 100.283 & 94 & 1.067 & 0.018 & 0.926 & 0.877 & 0.948 & 0.997 & 21.809 \\
& Full-metric invariance & 122.093 & 112 & 1.090 & 0.021 & 0.911 & 0.876 & 0.937 & 0.994 & $p>0.01$ \\
\hline \multirow{2}{*}{ Experiences } & Non-restricted model & 107.234 & 94 & 1.141 & 0.026 & 0.925 & 0.875 & 0.930 & 0.991 & 29.059 \\
& Full-metric invariance & 136.292 & 112 & 1.217 & 0.032 & 0.904 & 0.867 & 0.911 & 0.983 & $p>0.01$ \\
\hline
\end{tabular}

\subsubsection{Invariance Test of Structural Model}

A multi-group test for the causal path of the structural equation showed good fitness of baseline models for both gender $\left(\chi^{2}=185.061, \mathrm{df}=162, \chi^{2} / \mathrm{df}=1.142\right.$, RMSEA $=0.026$, $\mathrm{GFI}=0.898, \mathrm{AGFI}=0.848, \mathrm{NFI}=0.910, \mathrm{CFI}=0.988)$ and experiences $\left(\chi^{2}=187.543, \mathrm{df}=162\right.$, $\chi^{2} / \mathrm{df}=1.158, \mathrm{RMSEA}=0.028, \mathrm{GFI}=0.899, \mathrm{AGFI}=0.850, \mathrm{NFI}=0.887, \mathrm{CFI}=0.982$ ) groups The different parameters of the structural model were respectively restricted to form a series of nested models. The baseline model was compared with a series of nested models, and the significance of the difference of chi-square values between them was tested. The results were shown in Table 5. In gender groups, a significant difference was found in the relationship between attitude and purchase intention $(p<0.05)$, while the differences of the effects that subjective norms and perceived behavior control impacted on purchase intention were not significant $(p>0.05)$. Therefore, $\mathrm{H} 5$ was partly supported. In the experience groups, the differences between all the relationships are not significant $(p>0.05)$. H6 was thus not supported. Moreover, we further verify the double-moderating effect of gender and experiences on the relationship between attitude and purchase intention, the results (Table 6) showed that there was no significant difference between the effects of different gender's attitudes on the purchasing intention comparing among respondents with experience $(p>0.05)$, and comparing the influence of different genders' attitude on the purchasing intention among respondents without experience, the difference is 
significant $(p<0.05)$. Therefore, on the path between attitude and purchasing intention, purchasing experience has a double-moderating effect on the moderating effect of gender. The structural equation analysis results of gender group and experiences group were shown in Figures 1 and 2 respectively.

Table 5. Invariance tests of the structural models for gender and experiences groups.

\begin{tabular}{|c|c|c|c|c|c|}
\hline Gender & & & & & \\
\hline Paths & Men & Women & Baseline Model & Nested Model & Significances \\
\hline $\mathrm{PI}<-\mathrm{AT}$ & 0.066 & $0.492 * * *$ & $\chi^{2}(162)=185.061$ & $\chi^{2}(163)=190.954$ & Significant \\
\hline $\mathrm{PI}<-\mathrm{SN}$ & $0.613^{* * *}$ & $0.507^{* * *}$ & $\chi^{2}(162)=185.061$ & $\chi^{2}(163)=185.263$ & Not significant \\
\hline $\mathrm{PI}<-\mathrm{PBC}$ & $0.307^{* *}$ & 0.031 & $\chi^{2}(162)=185.061$ & $\chi^{2}(163)=187.999$ & Not significant \\
\hline \multicolumn{6}{|l|}{ Experiences } \\
\hline Paths & With PE & Without PE & Baseline model & Nested model & Significances \\
\hline $\mathrm{PI}<-\mathrm{AT}$ & 0.241 & $0.319^{* *}$ & $\chi^{2}(162)=187.543$ & $\chi^{2}(163)=187.585$ & Not significant \\
\hline $\mathrm{PI}<-\mathrm{SN}$ & $0.639^{* * *}$ & $0.470^{* * *}$ & $\chi^{2}(162)=187.543$ & $\chi^{2}(163)=187.887$ & Not significant \\
\hline $\mathrm{PI}<-\mathrm{PBC}$ & 0.117 & $0.255^{*}$ & $\chi^{2}(162)=187.543$ & $\chi^{2}(163)=188.400$ & Not significant \\
\hline
\end{tabular}

Note. ${ }^{*} p<0.05 ;{ }^{* *} p<0.01 ;{ }^{* *} p<0.001$.

Table 6. Invariance tests of the structural models for interacted groups between gender and experiences.

\begin{tabular}{cccccc}
\hline Paths & Men with PE & Women with PE & Baseline Model & Nested Model & Significances \\
\hline PI $<$-AT & 0.033 & $0.403^{*}$ & $\chi^{2}(162)=196.851$ & $\chi^{2}(163)=197.191$ & Not significant \\
\hline Paths & Men without PE & $\begin{array}{c}\text { Women without } \\
\text { PE }\end{array}$ & Baseline model & Nested model & Significances \\
\hline PI<-AT & 0.216 & $0.765^{* *}$ & $\chi^{2}(162)=167.999$ & $\chi^{2}(163)=174.600$ & Significant \\
\hline
\end{tabular}

Note. ${ }^{*} p<0.05 ;{ }^{* *} p<0.01$.

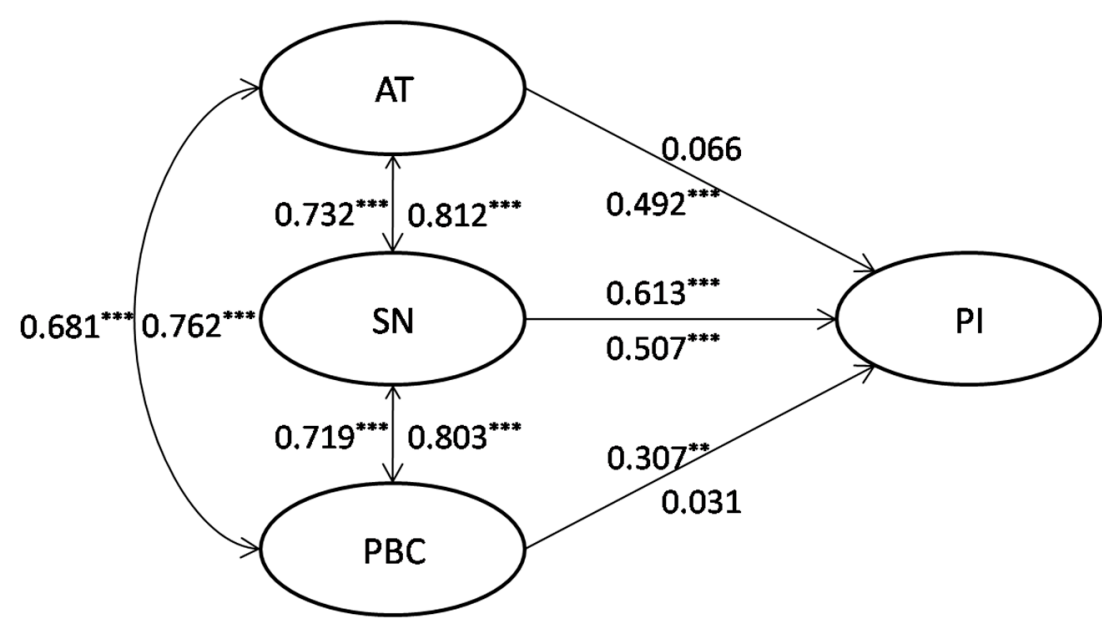

Figure 1. Structural equation analysis results of gender group. Note: the coefficients for the male group are at the left or top of the arrow, and the coefficients for the female group are at the right or bottom of the arrow. ${ }^{* *} p<0.01{ }^{* * *} p<0.001$. 


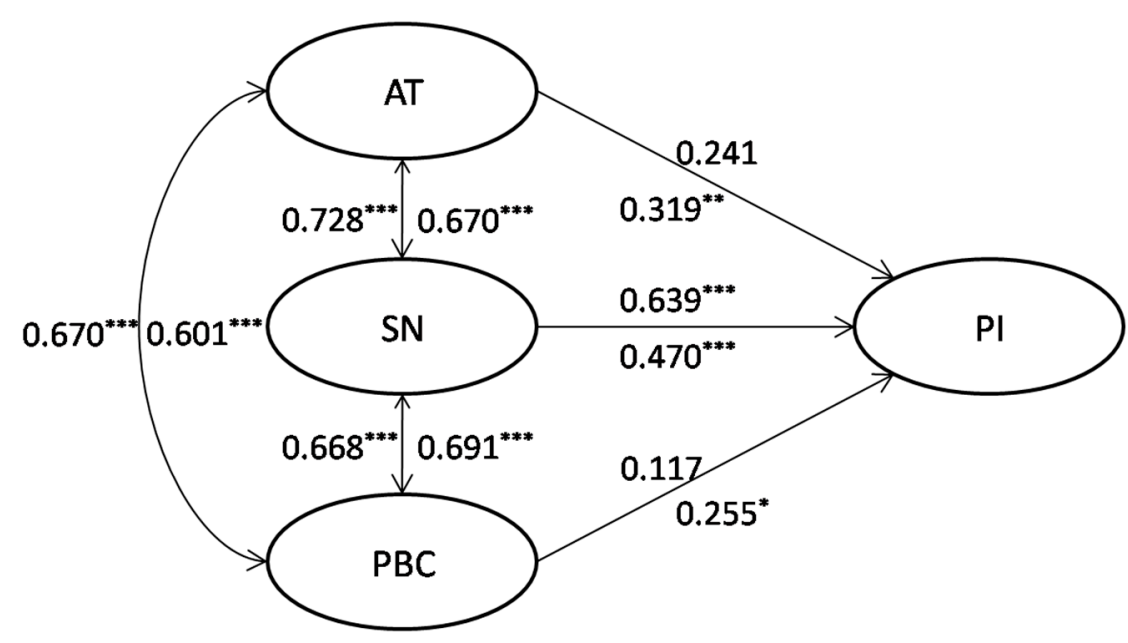

Figure 2. Structural equation analysis results of experiences group. Note: the coefficients for the with experiences group are at the left or top of the arrow, and the coefficient for the without experiences group is at the right or bottom of the arrow.* $p<0.05$; ${ }^{* *} p<0.01 ;{ }^{* * *} p<0.001$.

\section{Discussion}

Based on the TPB, this study analyzed the practicing of a green residence business model from the perspective of consumers' purchase decision-making. The results showed that TPB theory has a good explanatory power on consumers' willingness to buy green residence.

First, when consumers choose to buy green residence, their purchase intention will be significantly affected by behavioral attitude, subjective norms, and perceived behavioral control, which is consistent with the findings in extant studies $[32,39,40]$. However, the power of the impact is different. In this study, standard regression coefficients and $p$-values were compared, and the data showed that subjective norms had a greater impact on purchase intention than behavioral attitude and perceived behavioral control. Therefore, the first theoretical contribution of this study is to validate the TPB model in the field of green residence purchase decision-making. Second, this study attempted to explore the influence differences of different genders on each pathway under the TPB model. This study found that gender has a significant moderating effect on the influence of behavioral attitude on the purchase intention of green residence, and the influence of females is higher than that of males. Therefore, this study expanded the boundary of TPB model by exploring the difference of purchase intention between different genders. The possible reason for a higher effect that attitude impact has on purchase intention among females than on males is that female consumers are more environmentally concerned and in turn will generate more pro-environmental behaviors [41].In addition, it can be found from the comparison of the standard regression coefficients that in terms of the influence of subjective norms on purchase intention, men have a more significant effect than women. This may be due to the fact that men face greater social pressure than women in traditional Chinese families. In terms of the influence of perceived behavioral control on purchase intention, males are more likely than females to make decisions based on comprehensive information processing. This is contrary to the research conclusions of Darley et al. (1995) and Laroche et al. (2000) [21,22], which may be caused by cultural differences between the East and the West.

Third, this study attempted to explore the difference in the influence of purchase experience on each path under the TPB model. This study found that the purchase experience has no significant effect on the purchase decision of green housing. However, according to the comparison of the standard regression coefficients, it can still be found that in terms of the impact of behavioral attitude on purchase intention, consumers with purchase experience have a lower effect than those without purchase experience; in terms of the influence of subjective norms on purchase intention, the consumers with purchase experience have a higher effect than those without purchase experience. The influence of 
perceived behavioral control on purchase intention is smaller for consumers with purchase experience than for consumers without purchase experience.

Fourth, this study also attempts to explore the impact of the interaction between purchase experience and gender on each path under the TPB model. This study found that the gender difference in the impact of behavioral attitudes on the purchase intention of green housing mainly exists in the inexperienced consumer group. This indicates that although purchase experience does not directly regulate the relationship between the decision-making process and purchase intention, it has a double-moderating effect on the moderating effect of gender. This discovery further extended the boundary conditions of the TPB model. In view of the female consumers who many buy green residence for the first time, the effect of attitudes improvement that impact on the decision-making of green residence purchasing will be more significant.

\section{Conclusions}

In conclusion, this study verified that the TPB model can well explain the decisionmaking process of green residence purchasing in the context of China. Moreover, we also found a significant difference exists among consumers of different genders, especially among the people without experience.

These findings provided implications for practicing the green business model in real estate enterprise. First, it can be indicated that if we want to increase the purchase intention of customers for green residence, in terms of value proposition, we should pay more attention to improving the reputation of green residence, including the high praise from consumers' family and friends, extensive and positive comments from the media, and moderate guidance of policies, so as to improve their attitudes toward the purchasing behavior and subjective norms and in turn influence consumers to buy green residences. Second, considering green residence is a new type of housing form, it is necessary to popularize the knowledge related to green residence and its purchase, such as the characteristics of green residence and matters needing attention in purchase, which can increase their perceived behavioral control. Third, the above methods should be practiced by adopting more targeted ways for different customers, such as marketing for women focuses on the change of their attitudes, while the improvement of perceived behavioral control should be focused for men.

This study has its limitations. Firstly, the sample we used to test the hypotheses is from one city of China. Whether the results can be inferred in other parts of China depends on future studies. Further, we will extend the study to more cities in China, and even make comparative analysis among different countries, so as to expect more contributes to both research and practice. Secondly, it will be interesting also test the difference among the groups with different family income, education, and age; however, considering the thematic focus and space constraints, we plan to look at that in future studies. Finally, due to the constraints of research time and cost, the size of sample is relatively small, and further studies need to increase the sample size.

Author Contributions: Y.H. and S.L., conceived the idea and collected the data; Y.H., W.W. and C.W. analyzed and interpreted the data; Y.H. and W.W. drafted the manuscript; Y.H. and C.W. revised the manuscript; All authors have read and agreed to the published version of the manuscript.

Funding: This work was supported by the National Natural Science Foundation of China (Grant No. 71902042).

Institutional Review Board Statement: Not applicable.

Informed Consent Statement: Not applicable.

Data Availability Statement: The data presented in this study are available on request from the corresponding author.

Conflicts of Interest: The authors declare no conflict of interest. 


\section{References}

1. Primc, K.; Čater, T. The influence of organizational life cycle on environmental proactivity and competitive advantage: A dynamic capabilities view. Organ. Environ. 2015, 29, 212-230. [CrossRef]

2. FORA. Green Business Models in the Nordic Region: A Key to Promote Sustainable Growth; FORA: Copenhagen, Denmark, 2010.

3. Ajzen, I. The theory of planned behavior. Organ. Behav. Hum. Decis. Process. 1991, 2, 179-211. [CrossRef]

4. Ham, M.; Štimac, H.; Pap, A. Predicting the intention to purchase green food in Croatia-The influence of perceived self-identity. In Proceedings of the 24th CROMAR Congress, Split, Croatia, 22-24 October 2015.

5. Kim, H.; Chung, J. Consumer purchase intention for organic personal care products. J. Consum. Mark. $2011,1,40-47$.

6. Han, H.; Kim, Y. An investigation of green hotel customers' decision formation: Developing an extended model of the theory of planned behavior. Int. J.Hosp. Manag. 2010, 29, 659-668. [CrossRef]

7. Cronin, J.; Taylor, A. Measuring Service Quality: A Re-Examination and Extension. J.Mark. 1992, 50, 55-68. [CrossRef]

8. French, P.; Sutton, S.; Hennings, J.; Mitchell, J.; Nicholas, J.W.; Simon, G.; Wendy, H.; Kinmonth, L. The importance of affective beliefs and attitudes in the Theory of Planned Behavior: Predicting intention to increase physical activity. J. Appl. Soc. Psychol. 2005, 9, 1824-1848. [CrossRef]

9. Gopi, M.; Ramayah, T. Applicability of Theory of Planned Behavior in predicting intention to trade online: Some evidence from a developing country. Int. J. Emerg. Mark. 2007, 4, 348-360. [CrossRef]

10. Kim, Y.; Han, H. Intention to pay conventional-hotel prices at a green hotel? A modification of the theory of planned behavior. J. Sustain. Tour. 2010, 8, 997-1014. [CrossRef]

11. Numraktrakul, P.; Ngarmyarn, A.; Panichpathom, S. Factors Affecting Green Housing Purchase. In Proceedings of the 17th International Business Research Conference, Toronto, ON, Canada, 7-8 June 2012.

12. Al-Nahdi, T.; Habib, S.; Albdour, A. Factors influencing the intention to purchase real estate in Saudi Arabia: Moderating effect of demographic citizenship. Int. J.Bus. Manag. 2015, 10, 35. [CrossRef]

13. Taylor, S.; Todd, A. Understanding information technology usage: A test of competing models. Inf. Syst. Res. 1995, 62, 144-176. [CrossRef]

14. Venkatesh, V.; Davis, D. A theoretical extension of the Technology Acceptance Model: Four longitudinal field studies. Manag. Sci. 2000, 2, 186-204. [CrossRef]

15. Chan, C.; Lu, T. Understanding internet banking adoption and use behavior. J.Glob. Inf. Manag. 2004, 3, 21-43. [CrossRef]

16. Al-Momani, H. Structuring information on residential building: A model of preference. Eng.Constr. Archit. Manag. 2000, 2, 179-190. [CrossRef]

17. Jabareen, Y. Culture and housing preferences in a developing city. Environ. Behav. 2005, 1, 134-146. [CrossRef]

18. Kichen, M.; Roche, L. Life-care resident preferences. In Life Care: A Long-Term Solution? Chellis, R., Grayson, P., Eds.; Lexington: Lexington, MA, USA, 1990.

19. Kokilic, K.; Vida, I. Consumer strategic decision making and choice process: Prefabricated house purchase. Int. J.Consum. Stud. 2011, 6, 634-643. [CrossRef]

20. Teo, T.; Beng, L.C. Explaining the intention to use technology among student teachers. Campus-Wide Inf. Syst. 2010, 2, 60-67. [CrossRef]

21. Darley, W.; Smith, R. Gender differences in information processing strategies: An empirical test of the selectivity model in advertising response. J. Advert. 1995, 24, 41-56. [CrossRef]

22. Laroche, M.; Saad, G.; Cleveland, M.; Elizabeth, B. Gender differences in information search strategies for a Christmas gift. J. Consum. Mark. 2000, 17, 500-522. [CrossRef]

23. Laroche, M.; Bergeron, J.; Barbaro-Forleo, G. Targeting consumers who are willing to pay more for environmentally friendly products. J. Consum. Mark. 2001, 18, 503-520. [CrossRef]

24. Homburg, C.; Giering, A. Personal characteristics as moderators of the relationship between customer satisfaction and loyalty: An empirical analysis. Psychol. Mark. 2001, 18, 43-66. [CrossRef]

25. Robledo, J.; Aran, M. The moderating role of gender on entrepreneurial intentions: A TPB perspective. Intang. Cap. 2015, 11, 92-117.

26. Melnyk, V.; van Osselaer, S. Make me special: Gender Differences in consumers' responses to loyalty programs. Mark. Lett. 2012, 23, 545-559. [CrossRef]

27. Lee, J.; Back, K. Association meeting participation: A test of competing models. J. Travel Res. 2009, 46, 300-310. [CrossRef]

28. Oh, H.; Hsu, C. Volitional degrees of gambling behaviors. Ann. Tour. Res. 2001, 28, 618-637. [CrossRef]

29. Quellteet, A.; Wood, W. Habit and intention in everyday life: The multiple processes by which past behavior predicts future behavior. Psychol. Bull. 1998, 124, 54-74.

30. Perugini, M.; Bagozzi, P. The role of desires and anticipated emotions in goal-directed behaviors: Broadening and deepening the theory of planned behavior. Br. J.Soc. Psychol. 2001, 40, 79-98. [CrossRef]

31. Hoe, J.; Dastane, O.; Selvaraj, K. Predicting Consumer Perception and Its Impact on Purchase Intention for Residential Property Market. Available online: https://papers.ssrn.com/sol3/papers.cfm?abstract_id=3174624 (accessed on 14 June 2021).

32. Zhang, L.; Chen, L.; Wu, Z.; Zhang, S.; Song, H. Investigating Young Consumers' Purchasing Intention of Green Housing in China. Sustainability 2018, 10, 1044. [CrossRef] 
33. Zhang, Y.; Yuan, J.; Li, L.; Cheng, H. Proposing a Value Field Model for Predicting Homebuyers' Purchasing Behavior of Green Residential Buildings: A Case Study in China. Sustainability 2019, 11, 6877. [CrossRef]

34. Taylor, S.; Todd, A. Decomposition and crossover effects in the theory of planned behavior: A study of consumer adoption intentions. Int. J. Res. Mark. 1995, 12, 137-155. [CrossRef]

35. Ajzen, I. Constructing A TPB Questionnaire: Conceptual and Methodological Considerations. Available online: http://citeseerx. ist.psu.edu/viewdoc/download?doi=10.1.1.601.956\&rep=rep1\&type=pdf (accessed on 14 June 2021).

36. Yoon, C. Theory of planned behavior and ethics theory in digital piracy: An integrated model. J. Bus. Ethics 2011, 100, 405-417. [CrossRef]

37. Paul, J.; Modi, A.; Patel, J. Predicting green product consumption using theory of planned behavior and reasoned action. J. Retail. Consum. Serv. 2016, 29, 123-134. [CrossRef]

38. Han, H.; Hsu, L.; Lee, J. Empirical investigation of the roles of attitudes toward green behaviors, overall image, gender, and age in hotel customers' eco-friendly decision-making process. Int. J. Hosp. Manag. 2009, 28, 519-528. [CrossRef]

39. Maichum, K.; Parichatnon, S.; Peng, K.-C. Application of the Extended Theory of Planned Behavior Model to Investigate Purchase Intention of Green Products among Thai Consumers. Sustainability 2016, 8, 1077. [CrossRef]

40. Verma, V.K.; Chandra, B. An application of theory of planned behavior to predictyoung Indian consumers' green hotel visit intention. J. Clean. Prod. 2018, 172, 1152-1162. [CrossRef]

41. Matthes, J.; Wonneberger, A.; Schmuck, D. Consumers' green involvement and the persuasive effects ofemotional versus functional ads. J. Bus. Res. 2014, 67, 1885-1893. [CrossRef] 